\title{
Can Amputation Save the Hospital? The Impact of the Medicare Rural Flexibility Program on Demand and Welfare*
}

\author{
Gautam Gowrisankaran $^{\dagger} \quad$ Claudio Lucarelli ${ }^{\ddagger}$ \\ Philipp Schmidt-Dengler $\S \quad$ Robert Town $₫$
}

April 27, 2017

\begin{abstract}
This paper seeks to understand the impact of the Medicare Rural Hospital Flexibility (Flex) Program on hospital choice and consumer welfare for rural residents. The Flex Program created a new class of hospital, the Critical Access Hospital (CAH), which receives more generous Medicare reimbursements in return for limits on capacity and length of stay. We find that conversion to $\mathrm{CAH}$ status resulted in a 4.7 percent drop in inpatient admissions to participating hospitals, almost all of which was driven by factors other than capacity constraints. The Flex Program increased consumer welfare if it prevented the exit of at least 6.5 percent of randomly selected converting hospitals.
\end{abstract}

Keywords: Hospital Choice, Patient Welfare, Medicare.

JEL Classification: L11, L38, I11, I18

${ }^{*}$ Support from Agency for Healthcare Research and Quality (AHRQ) under grant 1R01HS018424-01A1 is gratefully acknowledged. We thank Dan Ackerberg and Ira Moscovice for helpful comments. Theresa Gutberlet, Anatolii Kokoza, Jianjing Lin, Kathleen Nosal, Mario Samano, Stephan Seiler and Zaiyan Wei provided excellent research assistance.

${ }^{\dagger}$ University of Arizona, HEC Montreal and NBER

${ }^{\ddagger}$ Universidad de los Andes

$\S$ University of Vienna, also affiliated with CEPR, CES-Ifo, and ZEW

IUniversity of Texas-Austin and NBER 


\section{Introduction}

Embedded in the Balanced Budget Act of 1997 was a provision creating the Medicare Rural Hospital Flexibility (Flex) Program. The Flex Program established a new class of hospitals under Medicare, Critical Access Hospitals (CAH), to which hospitals could convert. In order to obtain CAH status, hospitals are required to comply with a number of restrictions including limits on their capacity (25 beds or less) and on their patients' average length of stay (LOS). ${ }^{1}$ In return for accepting these constraints, CAHs receive cost-based reimbursements from Medicare that are typically more generous than those under the standard prospective payment system (PPS). The overarching purpose of the Flex Program is to improve and sustain access to quality healthcare services for rural residents. One important avenue through which the program sought to achieve this goal was through increasing the financial stability of rural hospitals which, in turn, was intended to spur improvements in the quality of patient care and reduce the likelihood of closure.

In the years since its implementation, the Flex Program has left a large imprint on the structure of rural hospital markets and costs of rural healthcare. Currently, over 1,330 rural hospitals - comprising 25 percent of all U.S. hospitals, 4 percent of all beds, and over half of rural hospitals - have CAH status. ${ }^{2}$ The Flex Program caused hospitals to shed significant amounts of capacity so that they could qualify for conversion. In 1996, 14 percent of rural hospitals had 25 beds or less, while that figure rose to 50 percent by 2005 . Of the hospitals that had converted to CAH status by 2006, 98 percent had more than 25 beds in 1996 . The mean capacity of eventual converters decreased from 42 beds in 1996 to 22 beds in $2005 .^{3}$ The program has also been costly: it is estimated that Medicare's payments to hospitals with CAH status have increased by 35 percent (MedPAC, 2005). Yet it has enjoyed wide

\footnotetext{
${ }^{1}$ The initial legislation also required CAHs to be distant from other hospitals but this requirement could be waived if the state in which the hospital was located deemed the hospital a necessary provider.

${ }^{2}$ http://www.flexmonitoring.org/data/critical-access-hospital-locations/

${ }^{3}$ Authors' calculations based on data described in Gowrisankaran et al. (2010).
} 
and bipartisan support, with multiple proposals for expansion. ${ }^{4}$

The scale of the Flex Program, its costliness, and its impact on the size distribution of rural hospitals all suggest that a policy evaluation of the consequences of the Flex Program is an important exercise to undertake. Moreover, the program embeds an interesting tension: participation provided benefits to firms but also imposed limitations on their actions. Specifically, in order to convert to $\mathrm{CAH}$ status, hospitals generally reduced their capacity and altered their service offerings. The lower capacity and its associated impact on other hospital characteristics as well as the constraints on LOS may make CAHs a less attractive option to patients and the physicians who refer them. However, to the extent that the Flex Program forestalled some exit, it increased (or at least prevented a larger decrease in) access to hospital services for rural residents. This dimension of the Flex Program likely increased consumer surplus. Thus, given the possible effects of the Flex Program, its net impact on rural residents is ambiguous. This tension is also found in other, large scale federal programs. ${ }^{5}$

In this paper, we focus on a single but important dimension of the welfare impact of the Flex Program: consumer surplus. Using detailed patient discharge data, we first examine the impact of CAH conversion on converting hospitals' inpatient populations. Specifically, we assess the impact of conversion on average patient severity, the number of inpatient services, and the distributions of diagnoses and insurance arrangements. This analysis provides us with a broad understanding of the impact of the program. We then estimate the patient/physician utility function from hospital choice using multinomial logit (MNL) specifications and use the estimates to calculate the impact of conversion on patient demand for and utility from the hospital. We estimate separate MNL models for different patient groups in order to be able to drill down and understand the disparate impacts of conversion across different health

\footnotetext{
${ }^{4}$ For instance, the proposed Critical Access Hospital Flexibility Act of 2009 (H.R. 668) based capacity calculations on occupied beds, thereby effectively raising the bed capacity threshold, while H.R. 487, also introduced in 2009, would again let states waive the 35-mile requirement for CAH designation. Both enjoyed bipartisan support.

${ }^{5}$ For example, agricultural price supports require farms to leave previously cultivated land idle at certain times (Roberts and Schlenker, 2013).
} 
insurance arrangements and diagnoses. Our data span the pre- and post CAH conversion eras which allows us to use a difference-in-difference identification strategy. ${ }^{6}$ Finally, we use the parameter estimates from the demand model to quantify the likely consumer welfare impact of the Flex Program by calculating the reduction in hospital exit that would be necessary to offset the consumer welfare impact of conversion.

We construct our analysis data from several different sources. Our principal dataset is inpatient discharge records for the states of Colorado, Iowa, North Carolina, Oregon, Washington, West Virginia and Wisconsin over the years 1998-2005. Each of these states has both large rural populations and many $\mathrm{CAH}$ conversions. The discharge data contain the identity of the hospital from which the patient was discharged as well as patient ZIP code, demographics, diagnoses, and the source of health insurance. We link these data to a variety of hospital characteristics, including the date of conversion to CAH status, if any. Our analysis data contain over 7 million patient observations.

We find that hospitals that ultimately converted to CAH status were different in observable ways from non-converting hospitals, even prior to conversion. The converting hospitals treated fewer patients and offered fewer services. Their patients were, on average, less severely ill, more likely to be Medicare enrollees, and traveled shorter distances. Moreover, upon conversion, CAHs saw a modest drop in the average number of diagnoses treated, and shifts in the distribution of the diagnoses treated. In contrast, mean patient age and severity of illness for converting hospitals did not substantially change following conversion.

Turning to our MNL demand and utility estimates, we find that CAH conversion would reduce patient utility, leading to a decline in inpatient volume. Overall, the drops in volume occurred fairly systematically across payor and diagnosis. For instance, conversion to $\mathrm{CAH}$ status led to a roughly 5 percent average decline in both Medicare and privately insured

\footnotetext{
${ }^{6}$ Our data begin in 1998, which is just after the Flex Program was passed, and before the vast majority of conversions occurred.
} 
admissions. $^{7}$

For the diagnoses that we investigated, conversion to $\mathrm{CAH}$ status resulted in a patient volume drop of between 2 and 12 percent. Some outliers include a relatively large decline of 8 percent for acute myocardial infarction patients and a relatively small decline of 2 percent for pneumonia patients. ${ }^{8}$

In our model, CAH conversion can affect utility through two different pathways. First, a bed size reduction can and does directly affect utility, perhaps because it proxies for the loss of a range of inpatient and outpatient services. Second, independent of bed size reductions, the $\mathrm{CAH}$ designation may impact the attractiveness of the hospital. For example, CAHs also receive cost-based reimbursements for outpatient services and CAHs may emphasize those services. In addition, restrictions on LOS may cause the hospital to drop services. We find that virtually all of the decline in demand from conversion is driven by factors that are unrelated to bed size reductions. This is true across the entire patient population and generally holds for patients with different insurance arrangements and different conditions.

Finally, we use our estimates from the hospital choice model to explore the policy tension in the Flex Program noted above. Even though the multinomial logit (MNL) parameters imply that $\mathrm{CAH}$ conversion reduces patient utility, if the Flex Program averted a sufficient number of hospital closures, this effect could overcome the reduction in consumer surplus associated with conversion. Specifically, we calculate the reduction in exit necessary for the Flex Program to increase consumer surplus, assuming that the exiting hospitals are randomly drawn from the set of eventual CAH converters. We find that the Flex Program increases average consumer surplus if it forestalled the exit of a random subset of 6.5 percent or more of converting hospitals. As a point of comparison, over the period 1999-2005, a total of 2.4

\footnotetext{
${ }^{7}$ These figures are the percentage drops in 2005 volume from all $2005 \mathrm{CAH}$ hospitals having their 1998 bed size and not having CAH status to them all having CAH status and their 2005 bed size. They are from our specifications that include bed size and interactions as regressors.

${ }^{8}$ Consistent with this, Lutfiyya et al. (2007) found that quality of pneumonia for CAHs is higher than urban hospitals but for all other measures of quality of care, CAHs performed more poorly.
} 
percent of rural hospitals and 5.6 percent for non-rural hospitals exited. ${ }^{9}$

The paper proceeds as follows. Immediately below we discuss the related literature. Section 2 describes the institutional features of the Flex Program. Section 3 describes our data and provides summary statistics. Section 4 presents our empirical model. Section 5 presents the estimates of the impact of the Flex Program on hospital demand and performs the welfare analysis. Section 6 concludes.

\section{Related literature}

Despite the importance of the Flex Program, there have been few national level evaluations of the program and even fewer papers that employ credible identification to assess the program's impact. In a preliminary analysis using ZIP code level data from Medicare's Health Services Area File (HSAF), Gowrisankaran et al. (2011) found that conversion to CAH status led to a precipitous decline in inpatient demand. However, further analysis revealed that the data likely contain non-random measurement error which probably explains the magnitudes of the estimated decline. This paper builds on our previous work by using higher quality, more accurate discharge data which allows for a richer demand system specification and the ability to examine the impact of conversion along patient demographic, insurance status, and disease dimensions.

Joynt et al. (2011) document that CAHs are less likely to have intensive care units, cardiac catheterization labs, and electronic medical records than other U.S. hospitals. More recent work documents that 46 percent of CAH have less than basic health information technology systems (Adler-Milstein et al., 2014). Furthermore, Joynt et al. find that patient outcomes are worse at CAHs relative to all other hospitals. Finally, Joynt et al. (p. 51) also refer to a number of recent studies that find negative to mixed impacts of CAH conversion on quality of care. Lutfiyya et al. (2007) find that rural CAHs perform significantly worse than urban hospitals on 7 out of 12 hospital quality indicators. Using data from Iowa, Li et al. (2007)

\footnotetext{
${ }^{9}$ Authors' calculations based on data described in Gowrisankaran et al. (2010).
} 
find that $\mathrm{CAH}$ conversion had a mixed impact on patient safety outcomes. The above papers identify the impact of conversion using cross-sectional information. As we show below, CAHs are meaningfully different from non-CAHs prior to their conversion. Thus, cross sectional analyses may be prone to biased inferences regarding the causal relationship between CAH status and hospital performance. We complement this body of research by using panel data with a difference-in-difference design and by modeling only rural hospitals.

Another literature analyzes financial aspects of the Flex Program. Stensland et al. (2003) and Stensland et al. (2004) study the financial effects of CAH conversion and find that conversion led to an increase in Medicare revenue and profit margins. Casey and Moscovice (2004) study the quality improvement initiatives of two CAHs after conversion, and conclude that the cost-based payments help the hospitals to fund activities that would improve quality of care such as additional staff, staff training, and new medical equipment.

Our work also relates to research that estimates the impact of hospital closures on welfare. Capps et al. (2010) note that while hospital closures reduce consumer surplus, they also reduce costs, thereby lowering required public subsidies. Using a framework similar to the one we employ here, they study five closures and find that cost reductions outweigh the gain in consumer surplus from keeping the hospital open. McNamara (1999) studies the pre-Flex Program impact of rural hospitals closures on consumer surplus and finds that the average compensating variation for the closure of the nearest rural hospital is about $\$ 19,500$ (1988 dollars) per sample hospitalization. Finally, Joynt et al. (2015) examines the impact of hospital closures on patient outcomes and finds little impact of hospital exit on mortality rates for Medicare beneficiaries. 


\section{The Flex Program}

The Medicare Rural Hospital Flexibility Program was authorized by Section 4201 of the Balanced Budget Act of 1997 (BBA). ${ }^{10}$ Under the Flex Program, hospitals could apply to state and federal agencies to convert to Critical Access Hospital status. To obtain approval from the Center for Medicare and Medicaid Services (CMS), hospitals needed to meet a number of requirements, most importantly limitations on bed size, LOS, and distance to other hospitals (which we detail below). Although the legislation did not specify the intent of these limitations, the likely purpose was to limit the financial exposure of the government and to limit CAHs to treat low acuity conditions for quality of care reasons.

In addition, CAHs were required to provide inpatient, laboratory, emergency care, and radiology services, consistent with the program goals of maintaining access to emergency and other care for rural residents. CAHs also needed to develop agreements with acute care hospitals regarding patient referral, communication, and emergency and non-emergency patient transportation. Each CAH also needed an agreement with its referral hospital for quality improvement or could choose to have that agreement with another organization. The BBA provided resources for hospitals to hire consultants to project revenues and costs and help determine whether a conversion strategy would be optimal for the hospital given its objectives. Upon conversion, CAHs receive cost-based Medicare reimbursements for inpatient, outpatient post-acute (swing bed), and laboratory services. Currently these payments are set to 101 percent of average accounting costs.

We now detail the bed size, LOS, and distance requirements for CAHs. The initial 1997 BBA legislation specified that CAHs could have a maximum of 15 acute inpatient beds and 25 total beds, including swing beds. ${ }^{11}$ LOS was limited to a maximum of 96 hours (4 days). Converting hospitals were required to be in rural areas and be at least 35 miles by primary

\footnotetext{
${ }^{10}$ Much of the information in the section is culled from MedPAC (2005), which contains much more background than we can provide.

${ }^{11} \mathrm{~A}$ swing bed is used to provide post-acute care.
} 
road and 15 miles by secondary road from the nearest other hospital. However, hospitals could (and often did) have the distance restriction waived by having their state declare themselves a "necessary provider." Currently, most CAHs are within 25 miles of another hospital.

Table 1: Key Changes Over Time to Flex Program

\begin{tabular}{|c|c|}
\hline Legislation & Key Changes Resulting from Legislation \\
\hline BBA 1997 & $\begin{array}{l}\text { - Flex Program established. } \\
\text { - Hospitals should operate no more than } 15 \text { acute beds and no more than } 25 \text { total } \\
\text { beds, including swing beds. } \\
\text { - All patients' LOS limited to } 4 \text { days. } \\
\text { - Only government and not-for-profit hospitals qualify. } \\
\text { - Hospitals required to be located in rural areas. } \\
\text { - Hospitals required to be at least } 35 \text { miles by primary road and } 15 \text { miles by } \\
\text { - Secondary road from nearest other hospital. } \\
\text { - States could waive the distance requirement by designating "necessary } \\
\text { providers." }\end{array}$ \\
\hline BBRA 1999 & $\begin{array}{l}\text { - LOS restriction changed to an average of } 4 \text { days. } \\
\text { - States could designate any hospital to be "rural" allowing CAHs to exist in } \\
\text { - MSAs. } \\
\text { - For-profit hospitals allowed to participate in the program. }\end{array}$ \\
\hline BIPA 2000 & $\begin{array}{l}\text { - Payments for MDs "on call" included in cost-based payments. } \\
\text { - Cost-based payments for post-acute patients in swing beds. }\end{array}$ \\
\hline MMA 2003 & $\begin{array}{l}\text { - Inpatient limit increased from } 15 \text { to } 25 \text { patients. } \\
\text { - Psychiatric and rehabilitation units allowed and did not count against the } 25 \\
\text { - Ped limit. } \\
\text { - Sayments increased to } 101 \text { percent of cost. } \\
\text { Starting in } 2006, \text { states could no longer waive the distance requirement. }\end{array}$ \\
\hline
\end{tabular}

Source: MedPAC (2005)

The program's rules have been modified several times since its inception. Table 1 summarizes the main legislative changes to the program over time. The most important of these changes are: starting in 1999, states were allowed to designate hospitals in Metropolitan Statistical Areas "rural" for CAH classification; starting in 2000, cost-based reimbursements were extended to patients in swing beds; starting in 2003, the acute inpatient limit was raised 
from 15 to 25 and reimbursements were increased from 100 to 101 percent of costs; and starting in 2006, states could no longer waive the distance requirements for new applications.

Allowing the treatment of post-acute care patients to be reimbursed on a cost basis dramatically increased the profitability of caring for those patients. According to MedPAC (2005), "[t]he shift from receiving SNF rates for post-acute patients to receiving estimated costs (which assume post-acute routine costs equal acute routine costs) resulted in a dramatic increase in post-acute care payments from $\$ 259$ per day before conversion to $\$ 1,016$ per day after conversion" (p. 163). These changes to the Flex Program provide variation in the benefits to $\mathrm{CAH}$ conversion within the study period which will change the profitability thresholds for conversion over time. Our difference-in-difference analysis identifies the consumer welfare effects of CAH conversion by exploiting this variation.

Since the intent of the Flex Program was to maintain access to hospital care for rural residents, it is useful to examine the changes in rural hospital structure since the implementation of the policy. Out of the 4,779 hospitals in the U.S. in 1994, 49.3 percent (or 2,355 total) were rural. $^{12}$ Figure 1 shows the annual number of $\mathrm{CAH}$ conversions and the fraction of CAHs among rural, general acute care hospitals in the U.S. before and during our sample period. ${ }^{13}$ Starting in 2000 and through 2004, roughly 150 hospitals per year converted to CAH status. We believe that the delay between the enactment of BBA in 1997 and the timing of conversion is due to the complexity and uncertainty in the application process, which requires large amounts of paperwork, inspection visits, and CMS approval. ${ }^{14}$ By 2005, over 40 percent of rural hospitals and 25 percent of all U.S. hospitals had adopted CAH status. Conversion rates declined after 2005, when the minimum distance requirements became mandatory.

Figure 2 shows a histogram of rural bed sizes for hospitals in 1996 and 2005, with the

\footnotetext{
${ }^{12}$ The facts and figures in the remainder of this section are derived from a national panel dataset on rural hospitals, discussed in Gowrisankaran et al. (2010). Section 3 discusses our analysis data, which focuses on a limited set of states for which we obtained discharge data.

${ }^{13} \mathrm{~A}$ few conversions occurred prior to 1997 due to pilot programs.

${ }^{14}$ For example, in the state of Washington, the application process has 18 steps, detailed at http://www.ruralcenter.org/sites/default/files/Flowchart.pdf.
} 


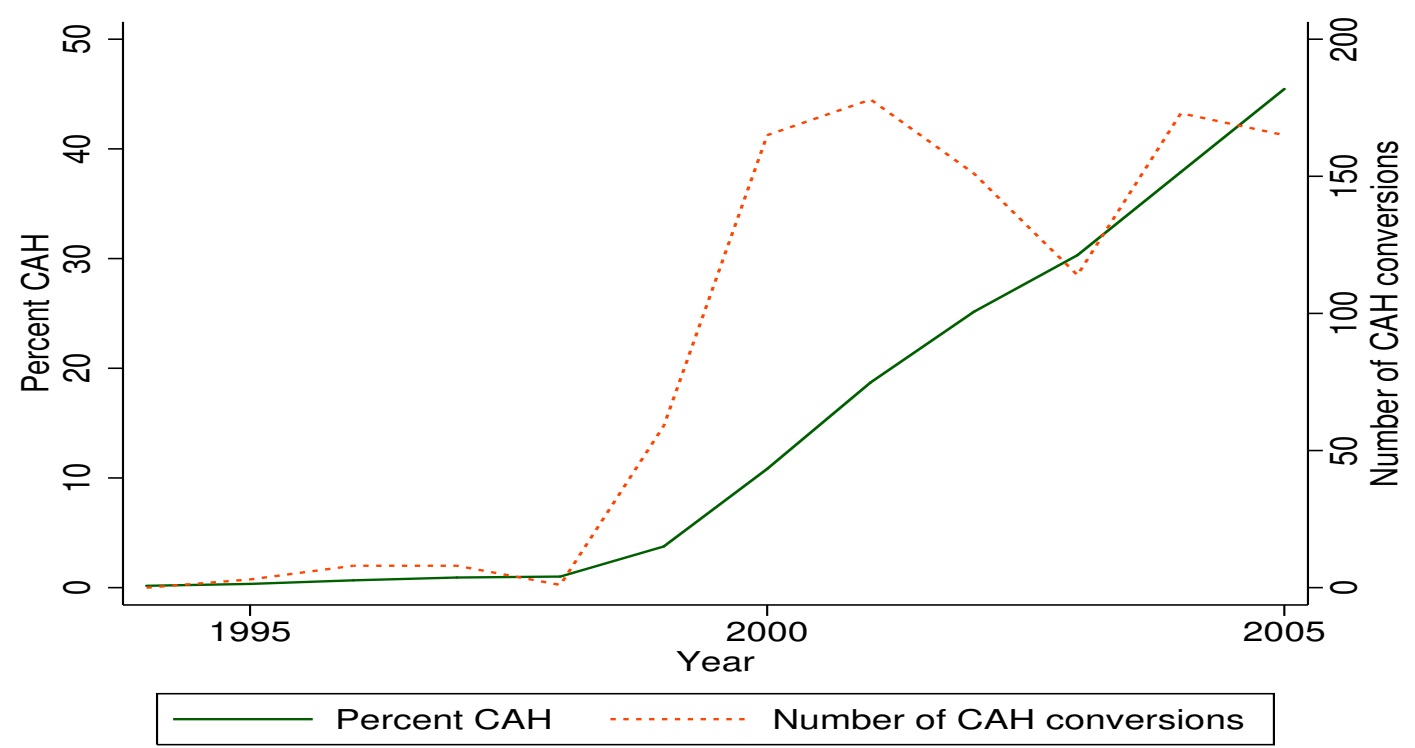

Figure 1: Conversions and percent CAH among U.S. rural hospitals

maximum truncated to $125 .^{15}$ The movement to CAHs has been accompanied by large drops in the bed size of rural hospitals. In 1996, the median bed size was 54. By 2005, the median bed size had dropped to 36 while the mean bed size went from 72 to 56 . Even more striking is that many hospitals dropped in bed size to exactly 25 - the upper-limit of the level allowed by the Flex Program. By 2005, 21 percent of rural hospitals had exactly 25 beds.

\section{Data}

To construct our analysis dataset, we link together information from several sources. Our primary data source is state inpatient discharge datasets. These data, which were acquired through the Agency for Healthcare Quality and Research's Health Care Utilization Project, provide discharge level information for virtually the universe of patients admitted to a hospital in that state. Each observation contains information on the discharging hospital, patient's home ZIP code, age, gender, primary payor, dates of admission and discharge, Diagnostic

\footnotetext{
${ }^{15}$ The sample for our main analysis extends from 1999 to 2005 due to availability of discharge data, but we have hospital characteristic data going back to 1996.
} 


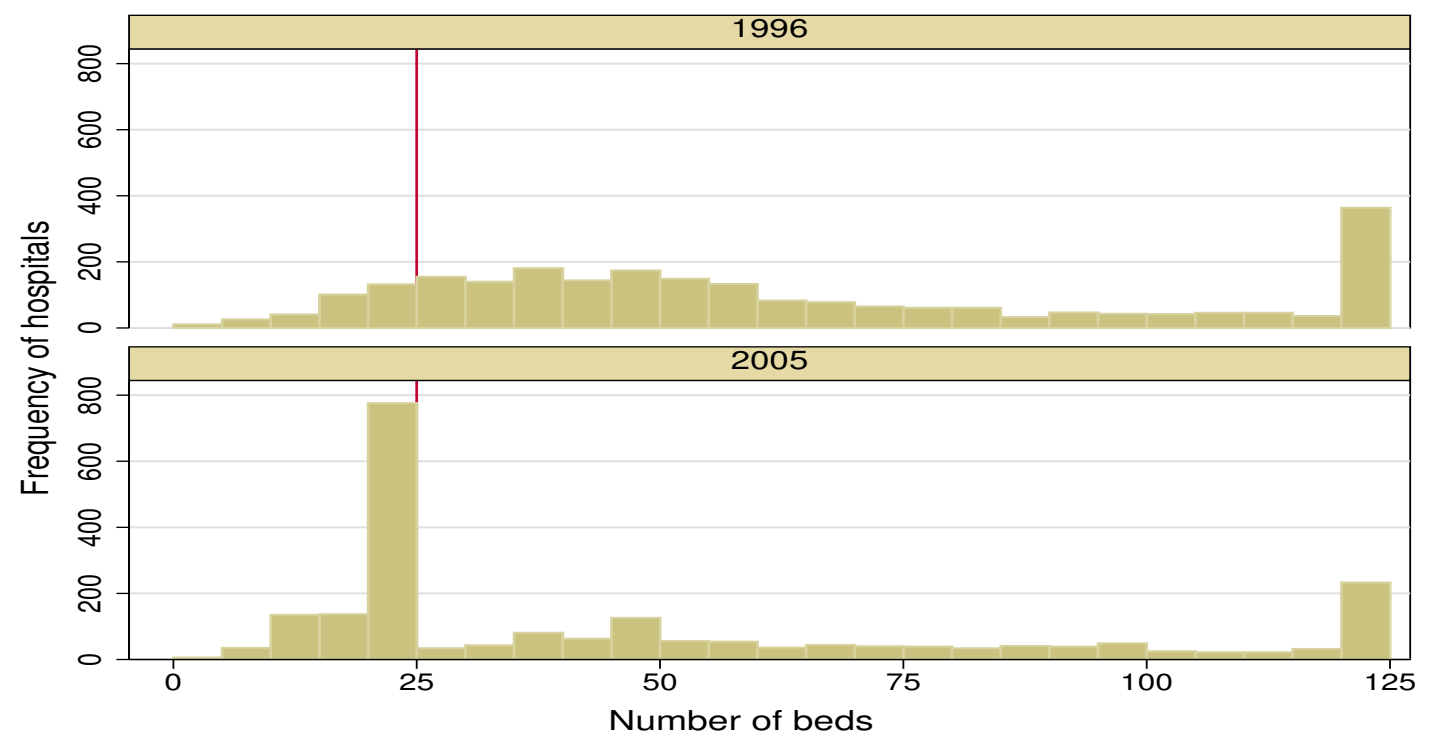

Figure 2: Size of rural hospitals, 1996 and 2005

Related Group (DRG), and principal diagnosis and procedure codes. DRGs are clusters of related diagnoses or procedures that use similar resources. Medicare uses DRGs to determine prospective payments for admissions to non-CAHs. Roughly, the hospital is paid the base rate times the DRG weight plus some adjustments. We merge in DRG weight information from CMS.

We use discharge data from seven states: Colorado, Iowa, North Carolina, Oregon, Washington, West Virginia, and Wisconsin. We selected these states due to data availability and because they each have sizable rural populations and a large number of CAH conversions. Within these states, we extract the sample of patients residing in rural areas. We focus on rural residents since the goal of the Flex Program is to improve healthcare access to those residents. The Colorado, Iowa, Washington State, and Wisconsin data span 1998 to 2005; the North Carolina and Oregon data are available from 2000 to 2005; and the West Virginia data begin in 2001 and end in 2005. ${ }^{16}$

Within these states, our analysis sample consists of patients residing in rural ZIP codes.

\footnotetext{
${ }^{16}$ To be included in the sample, a hospital must have at least 100 discharges over the 1998 to 2008 time frame.
} 
We define rurality using Rural-Urban Commuting Areas (RUCA) version 2.0. ${ }^{17}$ These measures of rurality are based on the size of cities and towns and their functional relationships, as identified by work commuting flows. RUCAs have been used by CMS to target CAHs and other rural policies, such as the ambulance payments. CMS considers all ZIP codes that have RUCA greater or equal to four to be rural and we adopt the same criterion in this paper.

We merge in data from the American Hospital Association (AHA), the Healthcare Cost Report Information System (HCRIS), the Census Bureau, and the Flex Monitoring Team. We pull in information on the hospital's latitude and longitude from the AHA. We link in hospital staffed bed size information from HCRIS. ${ }^{18}$ We use ZIP code centroid latitude and longitude data from the Census Bureau. Our data on the timing of CAH conversion come from the Flex Monitoring Team. ${ }^{19}$ In addition, the Flex Monitoring Team data contain accurate information on the number of staffed beds for the hospitals that converted.

$\mathrm{CAH}$ conversion may affect the range of services offered by the hospital as well as altering the types of providers working in the hospital. Thus, CAH conversion may differentially affect patient choice based on diagnosis. The detail in the patient discharge data allows us to analyze the impact of CAH conversion by specific diagnoses, Major Diagnosis Category (MDC), and type of insurance (Medicare and Privately Insured). ${ }^{20}$ MDCs are formed by combining the principal diagnosis codes into one of the 25 mutually exclusive categories corresponding to single organ system or etiology and, in general, are associated with a particular medical specialty.

Our dataset contains over 7 million patient discharges. Because of the size of the dataset,

\footnotetext{
${ }^{17}$ These measures are developed collaboratively by the Health Resources and Services Administration, the Office of Rural Health Policy, the Department of Agriculture's Economic Research Service, and the WWAMI Rural Health Research Center. WWAMI is a cooperative program with the University of Washington School of Medicine and the States of Washington, Wyoming, Alaska, Montana, and Idaho.

${ }^{18}$ The AHA also has information on bed size but the HCRIS data appears to be more accurate.

${ }^{19}$ The Flex Monitoring Team is a collaborative effort of the Rural Health Centers at the Universities of Minnesota, North Carolina and Southern Maine, under contract with the Office of Rural Health Policy. The Flex Monitoring Team monitors the performance of the Flex Program, with one of its objectives being the improvement of the financial performance of $\mathrm{CAH}$.

${ }^{20}$ Medicaid was coded inconsistently in the data for some states.
} 
it is impractical to estimate the parameters for some of our demand models. Therefore, in order to generate parameter estimates in a reasonable amount of time and maintain precision, we randomly sample patients so that the sample used to estimate the parameters has approximately 10 million hospital/patient observations. ${ }^{21}$

Table 2 presents summary statistics for our analysis data for the first and last years of our sample, 1998 and 2005 respectively. The first two columns present statistics from 1998 and hence include data from the four states which were in our sample in 1998 - Colorado, Iowa, Washington, and Wisconsin - while the last two columns present statistics from 2005 and hence include data from all seven states in our sample.

The first panel of Table 2 presents statistics at the hospital level for the entire sample. There were almost no CAHs in our sample in 1998 while 42 percent of the rural hospitals in our sample were CAHs by 2005. The number of beds at rural hospitals was similar for our analysis sample in 1998 and 2005, though these represent hospitals in different sets of states.

The second panel of Table 2 presents a more apples-to-apples comparison of the difference between 1998 and 2005 market structure by displaying the same set of statistics but restricting the sample to hospitals in the four states which were in our sample for the entire time period. The 1998 statistics are the same as in the first panel, by construction. Comparing the 2005 statistics to the 1998 ones, we find that the number of hospitals in our sample in these four states dropped from 420 to 396 while mean hospital size dropped from 107.0 beds to 95.66 beds over our sample period. Mean admissions per hospital increased about 17 percent, likely because of the fewer options available.

The third panel of Table 2 presents statistics at the patient level. The percentage of patients admitted to a CAH increased from essentially zero to 16 percent by 2005 . Approximately half of the patients were admitted to the hospital closest to their home. Patients traveled an average of $33.7 \mathrm{~km}$ (20.9 miles) to the hospital in 1998 and the average distance

\footnotetext{
${ }^{21}$ We selected 10 percent of the entire sample, 25 percent of the Medicare population and privately insured population, 50 percent of obstetrics and circulatory MDCs, and 25 percent of other MDCs.
} 
Table 2: Summary Statistics

\begin{tabular}{|c|c|c|c|c|}
\hline \multirow[b]{2}{*}{ Variable } & \multicolumn{2}{|c|}{1998} & \multicolumn{2}{|c|}{2005} \\
\hline & Mean & S.D. & Mean & S.D. \\
\hline \multicolumn{5}{|c|}{ Hospital Characteristics- Entire Sample } \\
\hline Number of Beds & 107.0 & 107.9 & 110.9 & 133.87 \\
\hline CAH & .002 & .049 & .420 & .494 \\
\hline Not-for-profit & .631 & 483 & 634 & 482 \\
\hline For-profit & .040 & 197 & .054 & .226 \\
\hline Admissions per Hospital & $1,483.7$ & $4,317.5$ & $2,072.7$ & $6,098.7$ \\
\hline Number of Hospitals & 420 & - & 500 & \\
\hline Hospital Characteristics - For Hosp & tals in $\mathrm{S}$ & ates in $\mathrm{S}_{\mathrm{s}}$ & ple for $\mathrm{E}$ & Period \\
\hline Number of Beds & 107.0 & 107.9 & 95.66 & 113.51 \\
\hline $\mathrm{CAH}$ & .002 & .049 & .490 & .500 \\
\hline Not-for-profit & 631 & 483 & 649 & 477 \\
\hline For-profit & .040 & 197 & .040 & 197 \\
\hline Admissions per Hospital & $1,483.7$ & $4,317.5$ & $1,730.3$ & $6,852.4$ \\
\hline Number of Hospitals & 420 & - & 396 & \\
\hline \multicolumn{5}{|c|}{ Patient Characteristics } \\
\hline Admitted CAH & .0006 & .000 & .155 & .362 \\
\hline Age & 50.1 & 28.8 & 51.4 & 28.0 \\
\hline Female & .582 & 493 & .583 & .493 \\
\hline Length of Stay & 4.01 & 5.21 & 4.15 & 5.41 \\
\hline DRG Weight & 1.15 & 1.13 & 1.19 & 1.19 \\
\hline Number of Diagnoses & 4.77 & 2.72 & 5.82 & 2.78 \\
\hline Bed Size of Admitting Hosp. & 121.1 & 124.4 & 160.0 & 185.0 \\
\hline Distance to Admitting Hosp. (km) & 33.7 & 29.7 & 32.6 & 29.0 \\
\hline Closest & .483 & .500 & 481 & .500 \\
\hline Private Insurance & .372 & 483 & .303 & 460 \\
\hline Medicare & .439 & .496 & 456 & .498 \\
\hline Medicaid & .114 & .318 & 171 & .377 \\
\hline Patient Observations & \multicolumn{2}{|c|}{623,146} & \multicolumn{2}{|c|}{$1,036,361$} \\
\hline
\end{tabular}


traveled in our data declined slightly by 2005. There was a large decline in the percentage of privately insured patients while the percentage of Medicare patients rose two percentage points.

\section{Empirical Model}

We model the discrete hospital choice decision of the patient conditional on deciding to receive inpatient treatment. Each period $t$, there is a set of patients $\mathbf{I}_{\mathbf{t}}=\left\{1, \ldots, I_{t}\right\}$, each of whom lives in a rural area. Individual patients, denoted by $i \in \mathbf{I}_{\mathbf{t}}$, seek inpatient treatment for their illnesses. Patients differ by their diagnoses, demographics, insurance status, and location. Each patient (potentially in consultation with her physician) observes the characteristics of the available hospitals and makes a discrete choice among all available hospitals in order to maximize her utility. Let $\mathcal{J}_{t}$ denote the set of hospitals active in period $t$. A patient $i$ 's choice set is all hospitals within $85 \mathrm{~km}$ (52.8 miles) of her location-which we denote $\mathcal{J}_{t}^{i} \subseteq \mathcal{J}_{t}$ —and the outside option. The inside option choice set includes both rural and non-rural hospitals within the this radius. The outside option corresponds to choosing a hospital outside of this radius.

We now detail the patient utility function. ${ }^{22}$ Denote the patient's diagnosis $d(i, t)$. Patient $i$ 's utility from an inpatient admission to hospital $j \in \mathcal{J}_{t}^{i}$ is given by

$$
u_{i j t}=\xi_{j d(i, t)}+w_{i j t} \beta+\varepsilon_{i j t},
$$

where $\xi_{j d}$ is the hospital time-invariant fixed effect for diagnosis $d, w_{i j t}$ is a vector of characteristics specific to the hospital and patient. The unobservable, $\varepsilon_{i j t}$, follows an i.i.d. Type I extreme value distribution and is observable to the patient but not the econometrician.

\footnotetext{
${ }^{22}$ In practice, the patient's choice of hospital is also influenced by the patient's physician preferences over hospitals. Under the assumption that the physician acts as an agent of the patient, the parameter estimates reflect patient preferences.
} 
Patients select the hospital in their choice set that generates the highest utility. The utility of the outside option (admission to a hospital greater than $85 \mathrm{~km}$ away) is normalized to $u_{i 0 t}=\varepsilon_{i 0 t}$. We include a parsimonious set of variables in $w_{i j t}$ in order to capture the potential impact of conversion on patient preferences. Table 3 lists the variables included in $w_{i j t}$.

Table 3: Variables in Utility Function Other Than Fixed Effects

\begin{tabular}{lll}
\hline \hline & \multicolumn{1}{c}{ Variables } \\
\hline CAH status & Distance $(\mathrm{km})$ & Distance $^{2}$ \\
Bed size & DRG Weight $\times$ Beds & Closest hospital \\
Distance $\times$ Beds & Distance $\times$ Closest & CAH Status $\times$ Distance \\
CAH Status $\times$ Closest & Ever CAH $\times$ Distance & Ever CAH $\times$ Closest \\
Ever CAH $\times$ Trend & CAH Status $\times$ DRG Weight & Year Indicators \\
\hline
\end{tabular}

Note: "Ever CAH" is an indicator for whether the hospital ever converted to CAH status.

CAH conversion has two sets of impacts on the characteristics of the hospitals. First, conversion changes the reimbursement structure of the hospital which can affect the hospital's staffing, wages, material inputs, capital investments, and services for long LOS patients. Second, conversion affects the hospital bed size which directly affects capacity and scale. In principle, we could directly model the role of capacity constraints in the demand equation (Conlon and Mortimer, 2013), but most hospitals are not capacity constrained. ${ }^{23}$ However, hospital bed size likely captures many dimensions of the hospital beyond simply the number of patients it can house at a given time. Reducing capacity, even if the hospital is not capacity constrained, may impact the attractiveness of the hospital to patients and their admitting physicians. For example, the indirect impact of a reduction in hospital scale may make the hospital less attractive to physicians in their admission decisions and shift the emphasis on the types of care provided and patients targeted.

\footnotetext{
${ }^{23}$ From both our conversations with policy experts and our analysis of the data, we believe that the vast majority of converting hospitals were not capacity constrained either pre- or post-conversion. For instance, using staffed beds as the denominator and the product of discharges and LOS as the numerator, we calculated that converting hospitals had an average capacity usage of 28 percent in 1998 .
} 
For this reason, we flexibly model the impact of CAH conversion on patient utility through $\mathrm{CAH}$ indicators and their interactions as well as through bed size and its interactions. While we believe that including beds in the choice specification is useful, an argument can be made that beds should not be included in the demand specification. Thus, we also estimate demand specifications that do not include the bed size variables. We include interactions of distance and an indicator for whether the hospital ever converts, and an indicator of whether the hospital was the closest to the patient in order to control for pre-conversion differences between $\mathrm{CAH}$ and non-CAHs. ${ }^{24}$

Let $\delta_{i j t}=\xi_{j d(i, t)}+w_{i j t} \beta$ denote the "mean utility" from being admitted to hospital $j$, for $j \in \mathcal{J}_{t}^{i}$. Given the distributional assumption on the errors, we can write the choice probabilities for patients as:

$$
P r_{i j t}=\frac{\exp \left(\delta_{i j t}\right)}{1+\sum_{k \in \mathcal{J}_{t}^{i}} \exp \left(\delta_{i k t}\right)}
$$

Price does not enter the patient's utility. There are two reasons for this. First, hospital prices for our broad set of hospitals are not available. Second, a majority of rural patients are covered by Medicare and do not face any price variation. While privately insured patients may face some cost sharing arrangements, the net amount of cost sharing is very low.

Given the distributional assumption on $\varepsilon_{i j t}$, it is straightforward to estimate the parameters using maximum likelihood. The patient utility parameters will be identified from the geographic variation in patient and hospital locations and the extent to which consumers choose hospitals based on characteristics such as distance, CAH status, and hospital size. Because we allow for hospital fixed effects, the effects of CAH status and bed size changes will be identified from the difference-in-difference. In contrast, if CAH conversion is correlated with unobservable hospital characteristics - which is likely given the high correlation

\footnotetext{
${ }^{24}$ We explored whether to include higher-order time trends interacted with an indicator for whether the hospital ever converted and found that the coefficients on the high-order terms were very small and not statistically significant.
} 
with observable characteristics - failure to include hospital fixed effects would bias the parameter estimates. Even with hospital fixed effects, it is possible that our coefficient estimates reflect time-varying changes in hospital attributes that correlate with conversion to CAH status. However, we seek to rule out this explanation by including a falsification test of patient utility on future CAH status.

We are also interested in evaluating the heterogeneity across patients in the impact of treatment at CAHs. Conversion implies that hospitals must abide by limitations on the number of available beds and the average LOS. Reducing capacity may diminish the scope economies of hospitals, which, as a consequence, may focus on more common, lower acuity conditions. If this were the case, then patients with more complex illnesses would be made relatively worse off by CAH conversion as hospitals shed high acuity and low prevalence services. In contrast, patients requiring urgent care may be less sensitive to the level of service provision and more sensitive to distance, and hence be less affected by conversion to $\mathrm{CAH}$ status (and therefore benefit from the program if it prevents exit). Because some conditions such as acute myocardial infarctions (AMIs) both require urgent care but also often necessitate complex medical treatments, the impact of the Flex Program for patients with these illnesses is even more ambiguous. In addition, the impact of conversion may differ by the type of health insurance as $\mathrm{CAH}$ conversion changes the reimbursements for Medicare patients but does not directly affect payments for the privately insured population. To account for heterogeneous impacts of conversion across patients, we estimate separate specifications for different populations defined by insurance status, specific diagnoses, and MDC.

We focus on five specific diagnoses: AMI, heart failure, hip fracture, pneumonia, and stroke. We chose these diagnoses because they all have high in-hospital mortality rates and thus are important conditions to monitor and, with the exception of hip fracture, they are 
relatively common afflictions. The conditions are defined using the principal ICD-9CM ${ }^{25}$ diagnosis field listed in the discharge data. We also analyze the seven most common MDCs: circulatory system, digestive system, injuries, mental diseases, musculoskeletal system, obstetrics/newborns, and respiratory system. We group the remaining MDCs into the "other" category.

\subsection{The Impact of Conversion on Patient Volume}

We calculate the impact of CAH conversion on the volume of discharges using the parameter estimates from the MNL model. To perform this calculation, we compare the change in expected volume of the eventual CAH hospital from conversion. ${ }^{26}$ That is, we calculate the average treatment effect on those hospitals that select into treatment (conversion). We now detail this calculation.

Given the parameter estimates, the expected volume of patients as a function of CAH status and bed size is given by:

$$
\operatorname{EVol}_{j t}\left(C A H_{j t}, B e d s_{j t}\right)=\sum_{i=1}^{I_{t}} \operatorname{Pr}_{i j t}
$$

We calculate the mean impact of hospital $j$ 's CAH conversion (for the converters) as:

$$
\Delta_{j t}^{C A H}=E V o l_{j t}\left(C A H_{j t}=1, B e d s_{j t}\right)-E V o l_{j t}\left(C A H_{j t}=0, B e d s_{j}^{p r e-C A H}\right)
$$

where we set $t=2005$ and where $B e d s_{j}^{p r e-C A H}$ is the 1998 bed size of the hospital (prior to conversion). Since patients choose among hospitals, the effect also depends on whether characteristics of other hospitals change. We primarily calculate and report the impact of CAH conversion assuming the simultaneous conversion of all hospitals but also investigate

\footnotetext{
${ }^{25}$ International Classification of Diseases, Ninth Revision, Clinical Modification

${ }^{26}$ We allow beds to adjust to the new level at the same time as conversion to CAH status. We found that beds played a very minor role in these results.
} 
the impact holding the characteristics of other hospitals constant.

\subsection{Consumer Welfare Analysis}

A focus of this paper is on quantifying the consumer welfare impact of the Flex Program. This program imposes an implicit policy trade-off. Hospitals receive more generous payments but must agree to substantial reductions in their capacity and average LOS. Statically, these constraints almost surely weakly reduce consumer welfare. However, a principal policy goal of the program is reduce the number of rural hospital exits by providing financial stability, which likely increases consumer surplus. Thus, the net impact of the program on consumers depends on whether the gain from forestalled hospital exit outweighed the consumer welfare loss from CAH conversion. In order to get a sense of this trade-off, we evaluate how much the Flex Program would have affected consumer welfare given a range of different assumptions on the level of hospital exit averted by the program.

We proceed as follows. First, note that consumer surplus can be expressed as:

$$
C S_{t}\left(\mathcal{J}_{t}\right)=\sum_{i=1}^{I_{t}} \ln \left(1+\sum_{j \in \mathcal{J}_{t}^{i}} \exp \left(\delta_{i j t}\right)\right)
$$

following Small and Rosen (1981)'s derivation. ${ }^{27}$ Using (5), we evaluate the difference in consumer surplus between the current environment and an environment where hospitals did not have CAH status but where some hospitals might have exited, as:

$$
\Delta C S_{t}\left(\mathcal{J}_{t}\right)=C S_{t}\left(\mathcal{J}_{t}\right)-E\left[C S_{t, N o C A H}\left(\mathcal{J}_{t, N o C A H}\right)\right],
$$

where $\mathcal{J}_{t, N o C A H}$ is a random counterfactual industry structure where some converters exited

\footnotetext{
${ }^{27}$ It is well-known that random utility models can overstate the value of product variety (Ackerberg and Rysman, 2005). The logit model is particular susceptible to this criticism as it is a thick tailed distribution. However, we estimate the utility model using individual data where the model well characterizes actual choices and thus mitigates the role of the error term in these welfare calculations.
} 
and $C S_{t, N o C A H}$ is consumer surplus with $\mathrm{CAH}$ indicators equal to 0 and bed sizes equal to pre-conversion levels (for converting hospitals that did not exit).

Each of our counterfactuals assumes that eventual CAH converters have equal probabilities of exit in the absence of the Flex Program. We simulate a number of different counterfactual exit probabilities, ranging from 0 to 15 percent. For each counterfactual exit probability, we calculate the change in expected consumer surplus using equation (6). We also report statistics on the mean distance to chosen and closest hospitals.

\section{$5 \quad$ Results}

\subsection{Summary Evidence of the Impact of CAH Conversion}

Table 4 presents summary evidence in 1998 and 2005 for the rural hospitals in our sample broken down by those institutions that eventually converted during our sample time frame and those hospitals that did not. ${ }^{28}$ There are two important themes that emerge from these statistics. First, converting hospitals are very different than non-converting hospitals along several dimensions prior to their conversion. Second, conversion reduces the relative number of patients.

Converting hospitals were significantly smaller (measured by admissions and bed size) prior to their conversion than non-converting hospitals. These hospitals had, on a patientweighted basis, 69 percent fewer beds (46 v. 150) than hospitals that did not convert. Future CAHs also treated approximately 63 percent fewer patients than non-converting hospitals prior to their conversion. Converting hospitals offered fewer services as measured by the number of unique DRGs treated. On average, future CAHs' patients were diagnosed with 60.1 unique DRGs while non-converters' patients spanned 107.6 unique DRGs. ${ }^{29}$

\footnotetext{
${ }^{28}$ Here we limit the analysis to patients admitted to hospitals that are continuously in our sample from 1998 to 2005.

${ }^{29}$ The fewer unique DRGs could also be a consequence of the size of the patient population. However,
} 
In addition to the differences in size and span of services in 1998 between converters and non-converters, the characteristics of the patient populations meaningfully differed between these two hospital classes. Patients admitted to eventual converters had a 25 percent shorter mean LOS and and a 29 percent lower average DRG weight. Future CAHs treated relatively more Medicare and less privately insured patients. The more generous payments that come with $\mathrm{CAH}$ conversion only apply to Medicare patients and thus it is not surprising that converting hospitals admitted more Medicare patients prior to conversion. Patients admitted to non-converting hospitals, on average, traveled much further (42 v. $17 \mathrm{~km})$ (26.1 v 10.6 miles) and were much more likely to bypass a closer hospital on their path to the admitting hospital. For eventual converters, 75 percent of their patients were admitted to the closest hospital, while for the non-converters, only 36 percent of their patients were admitted to the closest hospital.

Not only are converting hospitals meaningfully different than non-converting hospitals prior to their conversion, the summary statistics also suggest that conversion affected the size of the hospital and the distribution of the patient population (along a few dimensions) relative to non-converting hospitals. Not surprisingly, the mean bed size of the converting hospital dropped by approximately 50 percent. Non-converters saw a large increase in their volumes over our sample period. Somewhat surprisingly, however, patient volume for converters was virtually unchanged after $\mathrm{CAH}$ conversion. Converting hospitals experienced a modest decline in the number of services provided while non-converting hospitals showed a large increase in the number of unique DRGs over this period. ${ }^{30}$

In Table 5 we present the distribution of diagnoses and MDCs for converting and nonconverting hospitals for the first and last year of our sample. Prior to conversion, CAHs had a higher percentage of their patient load with pneumonia and heart failure than hospitals that controlling for the number of patients, future converters' patients spanned significantly fewer DRGs.

${ }^{30}$ Again, it is possible that the relative decline in the number of unique DRGs is driven by the decline in volume. We have estimated the impact of $\mathrm{CAH}$ status on the mean number of diagnoses in a fixed effects framework controlling for the volume of patents and this finding is robust. 
Table 4: Patient Characteristics By 2005 CAH Status

\begin{tabular}{|c|c|c|c|c|}
\hline \multirow[b]{2}{*}{ Variable } & \multicolumn{2}{|c|}{1998} & \multicolumn{2}{|c|}{2005} \\
\hline & Mean & S.D. & Mean & S.D. \\
\hline \multicolumn{5}{|c|}{ CAH in 2005} \\
\hline Number of Hospitals & 171 & & 171 & \\
\hline Mean Admissions & 775 & 533 & 773 & 525 \\
\hline Bed Size of Admitting Hosp. & 45.8 & 16.1 & 24.1 & 2.60 \\
\hline Age & 52.2 & 30.5 & 54.4 & 30.4 \\
\hline Female & .61 & .49 & .62 & .49 \\
\hline Length of Stay & 3.28 & 3.68 & 3.25 & 3.77 \\
\hline Length of Stay $>4$ Days & .20 & .40 & .18 & .39 \\
\hline DRG Weight & .89 & .59 & .87 & .56 \\
\hline DRG Weight > 1.5 & .10 & .30 & .086 & .28 \\
\hline Number of Unique DRGs & 60.1 & 33.0 & 57.8 & 31.3 \\
\hline Number of Diagnoses & 4.61 & 2.67 & 5.37 & 2.76 \\
\hline Distance to Admitting Hosp. & 16.9 & 18.7 & 17.1 & 19.0 \\
\hline Closest & .75 & .44 & .75 & .43 \\
\hline Private Insurance & .33 & .47 & .27 & .44 \\
\hline Medicare & .49 & .50 & .52 & .50 \\
\hline $\mathrm{N}$ & \multicolumn{2}{|c|}{132,626} & \multicolumn{2}{|c|}{132,129} \\
\hline \multicolumn{5}{|c|}{ Not $\mathrm{CAH}$ in 2005} \\
\hline Number of Hospitals & 166 & & 166 & \\
\hline Mean Admissions & 2,098 & 5,637 & 3,046 & 7,574 \\
\hline Bed Size of Admitting Hosp. & 149.5 & 139.6 & 129.1 & 144.4 \\
\hline Age & 49.6 & 28.2 & 51.4 & 27.8 \\
\hline Female & .57 & .50 & .57 & .50 \\
\hline Length of Stay & 4.35 & 5.77 & 4.21 & 5.88 \\
\hline Length of Stay $>4$ Days & .29 & .45 & .26 & .44 \\
\hline DRG Weight & 1.26 & 1.28 & 1.33 & 1.35 \\
\hline DRG Weight > 1.5 & .23 & .42 & .27 & .44 \\
\hline Number of Unique DRGs & 107.6 & 80.8 & 114.2 & 83.2 \\
\hline Number of Diagnoses & 4.88 & 2.75 & 5.78 & 2.80 \\
\hline Distance to Admitting Hosp. & 41.7 & 30.8 & 45.3 & 31.4 \\
\hline Closest & .36 & .48 & .32 & .47 \\
\hline Private Insurance & .39 & .50 & .35 & .48 \\
\hline Medicare & .42 & .49 & .44 & .50 \\
\hline $\mathrm{N}$ & \multicolumn{2}{|c|}{379,167} & \multicolumn{2}{|c|}{443,720} \\
\hline
\end{tabular}

Note: Mean admissions are unweighted across hospitals. Hospitals in sample are those that are in the data for all years. Patients are only counted if they reside in the same state as the hospital of admission. 
never converted and a smaller percentage of their load with AMI than the never-converters. Future CAHs also had a greater 1998 percentage of their load in the Digestive Track and Respiratory MDCs and a smaller 1998 percentage in the Mental Health and Musculoskeletal MDCs than the never-converters. Interestingly, after conversion, CAHs experience a large and statistically significant decline in the percentage of their patient load from AMI patients (45 percent) — which has a high acuity — and a modest (though still significant) rise in the percent from pneumonia patients. Correspondingly, there is a notable decline in the Circulatory System MDC for CAHs upon conversion. We also observe a statistically significant decline in the percent of discharges for Mental Diseases and a statistically significant increase in the percent of discharges for Musculoskeletal and Respiratory Diseases.

Table 5: Distribution of Specific Diagnoses and MDCs By 2005 CAH Status

\begin{tabular}{|c|c|c|c|c|c|c|}
\hline & \multicolumn{3}{|c|}{ CAH in 2005} & \multicolumn{3}{|c|}{ Not CAH in 2005} \\
\hline & \multicolumn{6}{|c|}{ Specific Diagnoses } \\
\hline & 1998 & 2005 & z-stat & 1998 & 2005 & z-stat \\
\hline AMI & 0.020 & 0.011 & $18.48^{* * *}$ & 0.028 & 0.025 & $9.99^{* * *}$ \\
\hline Heart Failure & 0.041 & 0.040 & 1.61 & 0.025 & 0.025 & -0.77 \\
\hline Hip Fracture & 0.003 & 0.003 & -0.72 & 0.002 & 0.002 & -0.01 \\
\hline Pneumonia & 0.077 & 0.087 & $-9.41^{* * *}$ & 0.036 & 0.036 & 0.63 \\
\hline \multirow[t]{3}{*}{ Stroke } & 0.029 & 0.022 & $10.98^{* * *}$ & 0.028 & 0.023 & $16.00^{* * *}$ \\
\hline & \multicolumn{6}{|c|}{ MDCs } \\
\hline & 1998 & 2005 & z-stat & 1998 & 2005 & z-stat \\
\hline Circulatory & 0.154 & 0.128 & $19.30^{* * *}$ & 0.175 & 0.175 & -0.17 \\
\hline Digestive & 0.116 & 0.114 & 1.58 & 0.086 & 0.088 & $-3.80^{* * *}$ \\
\hline Injury & 0.011 & 0.010 & 1.21 & 0.012 & 0.014 & $-9.28^{* * *}$ \\
\hline Musculoskeletal & 0.060 & 0.065 & $-5.11^{* * *}$ & 0.112 & 0.121 & $-12.40^{* * *}$ \\
\hline Mental Diseases & 0.027 & 0.018 & $14.32^{* * *}$ & 0.054 & 0.034 & $46.25^{* * *}$ \\
\hline Obstetrics & 0.234 & 0.228 & $3.67^{* * *}$ & 0.209 & 0.197 & $14.12^{* * *}$ \\
\hline Respiratory & 0.150 & 0.157 & $-4.54^{* * *}$ & 0.088 & 0.093 & $-7.59^{* * *}$ \\
\hline Other & 0.249 & 0.280 & $-18.44^{* * *}$ & 0.264 & 0.278 & $-15.09^{* * *}$ \\
\hline $\mathrm{N}$ & 132,626 & 132,129 & & 379,167 & 443,720 & \\
\hline
\end{tabular}

Note: Significance levels are for two-sided test for equality of proportions. 
In sum, CAHs were different from non-CAHs prior to their conversion. Conversion led to a large decline in mean bed size, a decline in their relative volume, a relative reduction in the number of services offered, and a reduction in the number of patients with high severity illnesses, despite the emergency room requirement.

\subsection{MNL Demand Estimates}

The summary statistics presented above suggest that conversion reduced hospital demand. Of course, these reduced form estimates are not robust to shifts in population or changes in the characteristics of other hospitals which could plausibly be correlated with $\mathrm{CAH}$ conversion. In this section we estimate parameters of the utility function for inpatient hospital choice for rural residents from the MNL model specified in Section 4. This allows us to quantify the impact of CAH conversion and capacity changes, as well as to perform welfare analyses on the impact of the Flex Program.

Our specifications include hospital fixed effects, an indicator for CAH status, measures of capacity, and interactions of $\mathrm{CAH}$ status with measures of distance. Because Table 4 shows that CAHs draw from a more local pool than other hospitals prior to conversion, we include interactions between hospitals that convert at some point in our sample and measures of distance. We call hospitals that convert at some point "Ever CAH." We include Ever $\mathrm{CAH}$ and an interaction of Ever $\mathrm{CAH}$ and a time trend to allow for the possibility that these hospitals had a declining utility over time. Thus, our results should be interpreted as pertaining to the impact of $\mathrm{CAH}$ treatment on hospitals that ultimately converted. Any inference to hospitals that did not convert should be made with caution. 


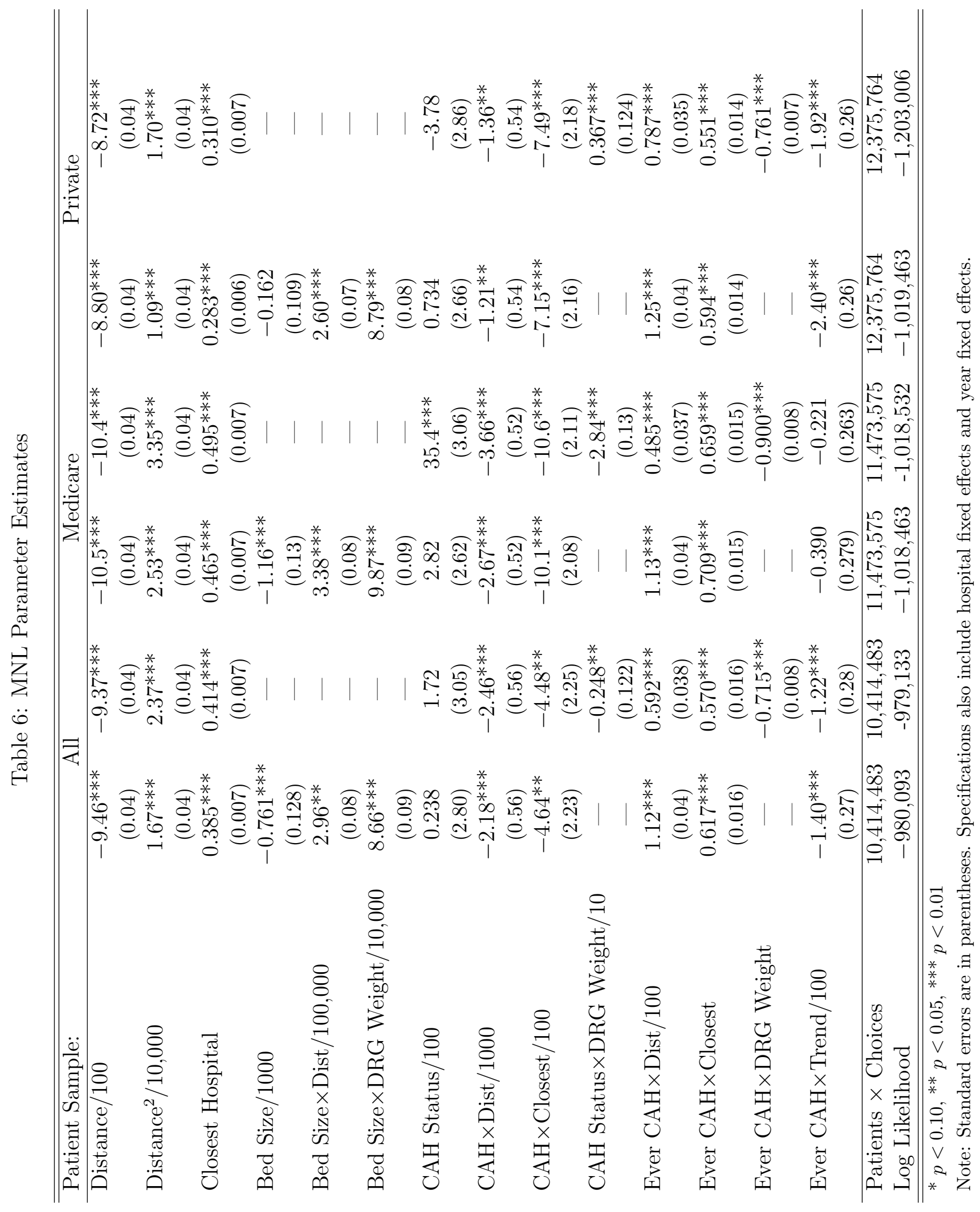


Table 6 presents the parameter estimates for six specifications, one per column. The first two columns are for the sample of all patients, the next two columns are for Medicare patients, and the final two columns are for private patients. In columns 1,3 , and 5 we include the number of staffed beds and its interaction with distance and DRG weight, an indicator for $\mathrm{CAH}$ conversion and interactions with distance, and an indicator of whether the hospital is the closest. Because there is some ambiguity as to whether it is appropriate to include beds, columns 2, 4, and 6 report coefficient estimates without staffed beds and interactions. In these three specifications, we also add an interaction of CAH status with the DRG weight. Tables 9 and 10 in the Appendix provide MNL parameter estimates for specific conditions and MDCs for the specifications with beds. ${ }^{31}$

The coefficient estimates in Table 6 closely align with expectations and the results from the hospital choice literature. Increasing distance to the hospital reduces utility but the impact is concave. Patients also have a strong preference for the hospital that is closest to them and the more severely ill the patient is (as measured by the DRG weight) the greater is the utility from larger hospitals and the less is the utility from CAHs. For both the sample as a whole and private pay patients, patient utility for hospitals that eventually converted was declining prior to conversion: the coefficient on Ever $\mathrm{CAH} \times$ Trend is negative and significant. However, for Medicare enrollees, this parameter is not significantly different from zero.

We may be concerned that our coefficients on CAH status reflect contemporaneous trends relating to those hospitals other than $\mathrm{CAH}$ status. In order to investigate this assumption, we estimated specifications with an indicator for conversion to CAH status in two years. In all cases, the inclusion of lead CAH indicators did not dramatically change the coefficients on the existing variables on CAH status. In some cases, some lead CAH indicators were marginally significant, and in other cases, not significant. ${ }^{32}$ We take from this exercise that these hospitals and markets may have had other time-varying factors, but that $\mathrm{CAH}$

\footnotetext{
${ }^{31}$ Results without beds for the specific conditions available from the authors.

${ }^{32}$ Results available from the authors.
} 
conversion likely did have a causal impact.

\subsection{Effects of CAH Conversion on Patient Volume}

Because our MNL results in Table 6 include many interactions of CAH status and bed size it is difficult to determine magnitudes directly from the coefficient estimates. For this reason, we use the MNL parameter estimates to calculate the mean impact of conversion on the number of admissions. Table 7 presents this information for each specification by insurance type and specific disease, and Table 8 presents the same information by MDC. Here we calculate the percentage change in 2005 volume for CAHs that is attributable to their conversion, based on the MNL coefficient estimates. We calculate the percentage change in volume assuming that all CAHs converted simultaneously using equation (4). ${ }^{33}$ For the specifications with beds, our simulations all set post-conversion bed size to their actual level. That being said, the primary impact of conversion on patient volume is almost exclusively through the CAH variable and not through bed size. ${ }^{34}$ Hence, we do not separately report the effects of bed size on volume.

Tables 7 and 8 show that CAH conversion significantly reduced patient volume and those reductions differ across payor class, diagnoses, and MDC. ${ }^{35}$ Using the sample with all patients and the specification with beds, CAH conversion reduces admissions, on average, by 4.7 percent. For the sample with all patients and the specification without beds, the estimated average reduction in admissions is slightly higher, at 5.0 percent.

\footnotetext{
${ }^{33}$ We have also calculated the change in volume from a given hospital's conversion assuming that no other hospital converted. These estimate look very similar to those presented in Tables 7 and 8 . The differences are generally less than one percentage point.

${ }^{34}$ For instance, for the sample with all patients, the change in bed size to 25 decreased volume slightly by 0.3 percent.

${ }^{35}$ We do not present standard errors as that would require bootstrapping or constructing high dimensional simulation from the asymptotic distribution of the parameters. Both of these approaches are very computationally intensive and would likely take many months to calculate on our computer cluster. We do note that most of the parameter estimates from the choice model are precisely estimated suggesting that these estimated effects should also be precisely estimated.
} 
The impact of conversion differs by the principal payor and specific condition. On average, using the specification with beds, conversion reduces Medicare volume by approximately 5.2 percent and privately insured volume by approximately 4.5 percent. Across the specific diagnoses, the largest reduction from conversion occurred in AMI patients and the smallest reduction was for pneumonia patients. These results align with the goals of the program to direct more acutely ill patients requiring more aggressive medical interventions away from CAHs. Most AMI patients are treated with reperfusion therapy, such as percutaneous coronary interventions (PCI) or clot-busting drugs. PCIs require the presence of a cardiac catheterization lab and the procedure is performed by an interventional cardiologist, neither of which are available to most CAHs. Of course, the treatment of AMI is time sensitive and it is possible that rural AMI patients are traveling further to receive care because of $\mathrm{CAH}$ conversion. Across MDCs, there is also significant variation in the volume response to conversion. The largest conversion response is for the Injuries MDC (a 12.2 percent decline) and the smallest decline is for the Respiratory MDC (2.9 percent decline). The estimates of the impact of CAH conversions without beds are, in general, very similar to the estimates from the base specification.

In sum, CAH conversion reduces the value that patients place on converting hospitals. There is heterogeneity in the impact across patients with different health insurance arrangements and diagnoses, with the biggest outliers being conditions of pneumonia, AMI, and the MDC of injuries. It is possible that the negative impact of $\mathrm{CAH}$ conversion is driven by the negative perception of quality of treatment in converted hospitals due to the findings in the medical literature (e.g. Joynt et al., 2011; Lutfiyya et al., 2007). Our results show that these findings are confirmed by patient choice data taking into account the heterogeneity of hospitals prior to conversion.

To understand the net impact of the Flex Program requires comparing this static welfare loss to any potential consumer surplus gained from the program forestalling exit. We explore 
that question next.

Table 7: Predicted Percentage Changes in Volume from Conversion to CAH Status

\begin{tabular}{lcc}
\hline \hline & Specification with beds & Specification without beds \\
\hline All & \multicolumn{2}{c}{ Results by Payor } \\
Medicare & -4.66 & -5.02 \\
Private & -5.20 & -5.64 \\
& -4.53 & -5.20 \\
\hline AMI & Results by Specific Diagnoses \\
Heart Failure & -8.15 & -5.70 \\
Pneumonia & -3.93 & -3.73 \\
Hip Fracture & -1.99 & -2.12 \\
Stroke & -3.95 & -3.92 \\
\hline \hline
\end{tabular}

Table 8: Predicted Percentage Changes in Volume from Conversion, by MDC

\begin{tabular}{lcc}
\hline \hline & Specification with beds & Specification without beds \\
\hline Circulatory & -6.64 & -6.42 \\
Digest & -3.39 & -3.87 \\
Injuries & -12.18 & -11.91 \\
Musculoskeletal & -5.38 & -6.11 \\
Mental Diseases & -4.24 & -6.37 \\
Obstetrics & -4.69 & -6.13 \\
Respiratory & -2.89 & -3.14 \\
Other & -7.30 & -6.59 \\
\hline \hline
\end{tabular}

\subsection{Consumer Welfare Effects of the Flex Program}

One of the principal goals of the Flex Program is to prevent rural hospital exit. As we have shown above, conversion to CAH status reduces patient utility. In our first welfare analysis, we quantify the loss in consumer welfare from $\mathrm{CAH}$ conversion using a distance metric. The policy tension in the Flex Program is between the increase in consumer surplus attributable 
to maintaining access to these hospitals by preventing exit and the decrease in consumer surplus associated with CAH conversion. In our second welfare analysis, we calculate the reduction in average entry rates over our sample period necessary for the Flex Program to increase rural resident welfare. We are only focused on consumer surplus in these analyses and do not attempt to account for the costs of administering the program, the costs of CAH conversion, changes in hospital profits, and changes in insurer profits. Our welfare effects use the estimates from our specification with beds from the entire sample (column 1 of Table 6) but our results are very similar to those from the specification without beds. ${ }^{36}$

We first compute the distance that leaves the patient indifferent between a non-CAH with a capacity of 42 beds (the mean size of CAHs prior to conversion) and a CAH with 25 beds and the same other characteristics. Specifically, using equation (1), we find the decrease in distance, $\Delta$ dist, that makes a patient with DRG weight 1 indifferent between admission to a $\mathrm{CAH}$ and a non-CAH for a given set of hospital characteristics. That is, we find the value of $\Delta$ dist $^{*}$ that solves $\delta_{i j t}\left(C A H=1\right.$, beds $=25$, dist $\left.-\Delta d i s t^{*}\right)=\delta_{i j t}(C A H=0$, beds $=42$, dist $)$ where $\delta_{i j t}(\cdot)$ is the mean utility function, evaluated at the estimated parameter values and with the noted values of $\mathrm{CAH}$ and bed size.

Because preferences are nonlinear in distance, we examine two cases: a hospital that is 10 $\mathrm{km}$ (6.2 miles) away from a patient and the closest to the patient's home and a hospital that is located $25 \mathrm{~km}$ (15.7 miles) away and not the closest to the patient's home. In the first case, patients with DRG weight 1 would be indifferent between the hospital converting to CAH status and moving $0.88 \mathrm{~km}$ (0.55 miles) closer to their home and the hospital not converting and remaining where it is. In the second case, patients would be indifferent between the hospital converting and moving $1.48 \mathrm{~km}$ (0.92 miles) closer to their home and the hospital not converting and remaining where it is. Thus, according to this distance metric, the welfare loss from conversion is modest but meaningful.

\footnotetext{
${ }^{36}$ The welfare results for the specifications with beds available from the authors.
} 
To implement our second and principal welfare analysis, we calculate the mean consumer surplus under different hospital exit scenarios over the entire period for hospitals that converted. We also calculate the mean distance to the closest hospital and average distance traveled to the chosen hospital. As we are interested in comparing the welfare under the Flex Program to the counterfactual in which the Flex Program was not enacted, our counterfactual considers the case where there are no CAHs and converting hospitals are assigned their pre-conversion capacity. In order to avoid having to estimate a dynamic firm model of exit in the absence of the Flex Program, we consider scenarios where the likelihood of exit is random across CAHs.

The results from this welfare analysis are presented in Figure 3. In the figure, we graph the percentage change in consumer surplus, distance to closest hospital, and distance to chosen hospital relative to those values under the Flex Program. The results in Figure 3 highlight the policy tension in the Flex Program. The break-even point for consumer surplus is an exit probability of approximately 6.5 percent. In other words, if the $\mathrm{CAH}$ program forestalled a random 6.5 percent or more of exit among CAH converters, its impact on consumer surplus for rural residents would be weakly positive. Moreover, our assumption that the set of exiting hospitals is conditionally random likely makes the above figure conservative, in the sense that the program was likely consumer welfare improving even if the forestalled exit among CAH converters was somewhat less than 6.5 percent. ${ }^{37}$

By construction, for all strictly positive averted exit probabilities, exit of CAHs would have resulted in an increase in the mean distance to the closest hospital. Exit of CAHs would have also resulted in an increase in the mean distance to the chosen hospital, but with a much less steep slope as a function of exit. The slope is less steep because of the fact that patients are willing to travel longer distance to avoid CAHs. At the break-even consumer welfare

\footnotetext{
${ }^{37}$ Extra exit in the absence of the $\mathrm{CAH}$ program would have likely occurred by hospitals that were less valued than average by patients. Thus, if we were to endogenize the exit decision in the absence of the CAH program with a model of firm exit, instead of calculating a random exit decision, an averted 6.5 percent exit probability would likely be strictly welfare improving.
} 
averted exit probability of 6.5 percent, mean distance to the closest hospital would have been about 5.2 percent higher and mean distance to the chosen hospital about 2.5 percent higher in the absence of the Flex Program.

Determining the counterfactual exit probability is challenging and requires solving for exit decisions by firms in the absence of the Flex Program, which in turn requires modeling the dynamic oligopoly interactions of hospitals. This is a task that we take up in companion work (Gowrisankaran et al., 2010).

Figure 3: Impact of Flex Program by Counterfactual Exit Probability

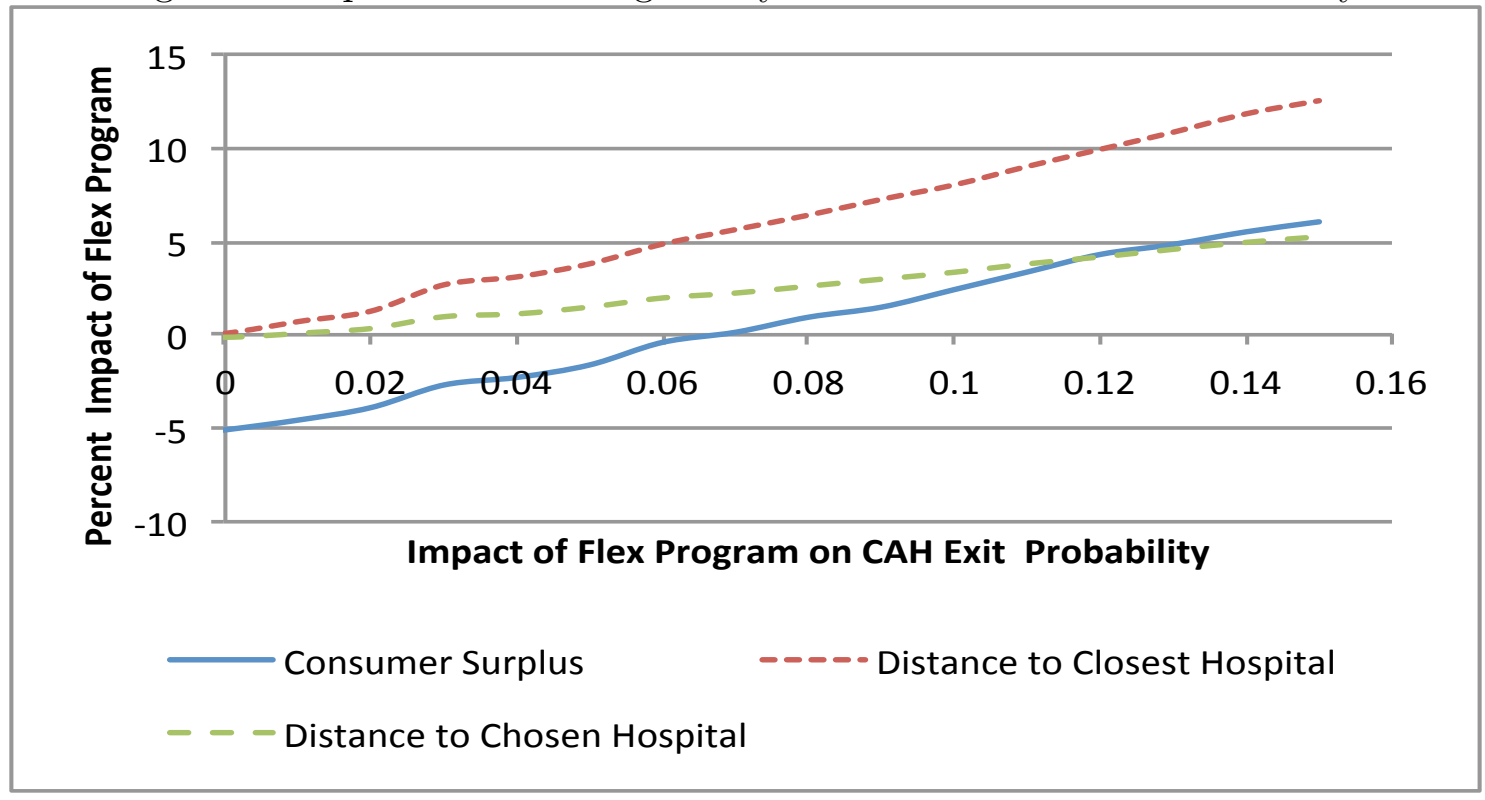

\section{Conclusions}

This paper estimated the impact of the Medicare Rural Flexibility Program on the demand for inpatient services. We find that patients are willing to travel significant distances to avoid visiting a Critical Access Hospital that faces LOS restrictions and consequently specializes in a limited range of services. The reduction of bed capacity to fulfill the $\mathrm{CAH}$ bed limit of 25 beds appears to have affected patient choice only in a minor fashion. We examine to what extent the impact of $\mathrm{CAH}$ conversion varies by condition and type of health insurance 
arrangement. The results suggest that while the magnitude of the $\mathrm{CAH}$ effect varies by condition, CAH conversion reduces the desirability of a hospital across most conditions and health insurance arrangements.

We calculate that the consumer welfare loss from $\mathrm{CAH}$ conversion will offset reduced exit from the Flex Program if a random 6.5 percent of $\mathrm{CAH}$ converters would have exited in the absence of the program. Changes in the quality of care provided by these hospitals may swamp the dimensions of welfare we consider here. In ongoing research, we examine the quality consequences of the Flex Program. While understanding the impact of the Flex Program on rural hospital exit is beyond the scope of this paper, Gowrisankaran et al. (2010) specify a dynamic oligopoly model with hospital exit and conversion to CAH status. Their aim is to compute counterfactual equilibrium market structures in order to examine the impact of eliminating and modifying the Flex Program on access to hospitals and patient welfare. 


\section{References}

Ackerberg, D. A. and Rysman, M. (2005). Unobserved product differentiation in discretechoice models: Estimating price elasticities and welfare effects. RAND Journal of Economics, 36(4):771-788.

Adler-Milstein, J., DesRoches, C. M., Furukawa, M. F., Worzala, C., Charles, D., Kralovec, P., Stalley, S., and Jha, A. K. (2014). More than half of us hospitals have at least a basic ehr, but stage 2 criteria remain challenging for most. Health Affairs, 33(9):10-1377.

Capps, C., Dranove, D., and Lindrooth, R. C. (2010). Hospital closure and economic efficiency. Journal of Health Economics, 29(1):87-109.

Casey, M. and Moscovice, I. (2004). Quality improvement strategies and best practices in critical access hospitals. Working Paper.

Conlon, C. T. and Mortimer, J. H. (2013). Demand estimation under incomplete product availability. American Economic Journal: Microeconomics, 5(4):1-30.

Gowrisankaran, G., Lucarelli, C., Schmidt-Dengler, P., and Town, R. (2010). Government policy and the dynamics of market structure: Evidence from critical access hospitals. Working Paper.

Gowrisankaran, G., Lucarelli, C., Schmidt-Dengler, P., and Town, R. (2011). The impact of the medicare rural hospital flexibility program on patient choice. International journal of industrial organization, 29(3):342-344.

Joynt, K., Harris, Y., Orav, J., and Jha, A. (2011). Quality of care and patient outcomes in critical access rural hospitals. Journal of the American Medical Association, 306(1):45-52.

Joynt, K. E., Chatterjee, P., Orav, E. J., and Jha, A. K. (2015). Hospital closures had 
no measurable impact on local hospitalization rates or mortality rates, 2003-11. Health Affairs, 34(5):765-772.

Li, P., Schneider, J. E., and Ward, M. (2007). Effect of critical access hospital conversion on patient safety. Health Services Research, 42(6):2089-2108.

Lutfiyya, M. N., Bhat, D. K., Gandhi, S. R., Nguyen, C., Weidenbacher-Hoper, V. L., and Lipsky, M. S. (2007). A comparison of quality of care indicators in urban acute care hospitals and rural critical access hospitals in the united states. International Journal for Quality in Health Care, 19(3):141-149.

McNamara, P. (1999). Welfare effects of rural hospital closures: a nested logit analysis of the demand for rural hospital services. American Journal of Agricultural Economics, 81(3):686-691.

MedPAC (2005). Report to congress: Issues in a modernized medicare program, Chapter 7.

Roberts, M. J. and Schlenker, W. (2013). Identifying supply and demand elasticities of agricultural commodities: Implications for the us ethanol mandate. The American Economic Review, 103(6):2265-2295.

Small, K. and Rosen, H. (1981). Applied welfare economics with discrete choice models. Econometrica, 49(1):105-130.

Stensland, J., Davidson, G., and Moscovice, I. (2003). The financial effects of critical access hospital conversion. Working Paper.

Stensland, J., Davidson, G., and Moscovice, I. (2004). The financial benefits of critica access hospital conversion for fy1999 and fy 2000 converters. Working Paper. 


\section{Appendix}

Table 9: MNL Parameter Estimates for Specific Diagnoses for all Payer Types

\begin{tabular}{|c|c|c|c|c|c|}
\hline & AMI & Heart Failure & Pneumonia & Hip Fracture & Stroke \\
\hline Distance/100 & $\begin{array}{c}-7.97^{* * *} \\
(0.09)\end{array}$ & $\begin{array}{c}-13.1^{* * *} \\
(0.08)\end{array}$ & $\begin{array}{c}-15.6^{* * *} \\
(0.08)\end{array}$ & $\begin{array}{c}-13.5^{* * *} \\
(0.33)\end{array}$ & $\begin{array}{c}-10.4^{* * *} \\
(0.08)\end{array}$ \\
\hline Distance $^{2} / 10,000$ & $\begin{array}{c}-0.377^{* * *} \\
(0.094)\end{array}$ & $\begin{array}{c}3.82^{* * *} \\
(0.09)\end{array}$ & $\begin{array}{c}6.26^{* * *} \\
(0.08)\end{array}$ & $\begin{array}{c}4.64^{* * *} \\
(0.36)\end{array}$ & $\begin{array}{c}1.87^{* * *} \\
(0.09)\end{array}$ \\
\hline Closest Hospital & $\begin{array}{c}0.772^{* * *} \\
(0.018)\end{array}$ & $\begin{array}{c}0.367^{* * *} \\
(0.014)\end{array}$ & $\begin{array}{c}0.152^{* * *} \\
(0.012)\end{array}$ & $\begin{array}{c}0.342^{* * *} \\
(0.061)\end{array}$ & $\begin{array}{c}0.558^{* * *} \\
(0.015)\end{array}$ \\
\hline Bed Size/1000 & $\begin{array}{c}-3.42^{* * *} \\
(0.26)\end{array}$ & $\begin{array}{c}-2.50^{* * *} \\
(0.27)\end{array}$ & $\begin{array}{c}-0.918^{* * *} \\
(0.263)\end{array}$ & $\begin{array}{c}-2.39^{* *} \\
(1.18)\end{array}$ & $\begin{array}{c}-0.895^{* * *} \\
(0.257)\end{array}$ \\
\hline $\begin{array}{l}\text { Bed Size× } \\
\text { Dist/100,000 }\end{array}$ & $\begin{array}{c}4.62^{* * *} \\
(0.15)\end{array}$ & $\begin{array}{c}4.56^{* * *} \\
(0.16)\end{array}$ & $\begin{array}{c}3.37^{* * *} \\
(0.17)\end{array}$ & $\begin{array}{c}5.25^{* * *} \\
(0.65)\end{array}$ & $\begin{array}{c}4.63^{* * *} \\
(0.15)\end{array}$ \\
\hline $\begin{array}{l}\text { Bed Size } \times \text { DRG } \\
\text { Weight } / 10,000\end{array}$ & $\begin{array}{c}12.5^{* * *} \\
(0.15)\end{array}$ & $\begin{array}{c}8.81^{* * *} \\
(0.18)\end{array}$ & $\begin{array}{c}6.58 * * * \\
(0.21)\end{array}$ & $\begin{array}{c}10.7^{* * *} \\
(0.65)\end{array}$ & $\begin{array}{c}5.36^{* * *} \\
(0.17)\end{array}$ \\
\hline CAH status/100 & $\begin{array}{l}-10.1 \\
(7.32)\end{array}$ & $\begin{array}{l}0.652 \\
(4.95)\end{array}$ & $\begin{array}{c}4.63 \\
(3.75)\end{array}$ & $\begin{array}{c}7.66 \\
(19.8)\end{array}$ & $\begin{array}{l}-6.04 \\
(5.92)\end{array}$ \\
\hline $\mathrm{CAH} \times$ Dist $/ 1000$ & $\begin{array}{l}0.699 \\
(1.49)\end{array}$ & $\begin{array}{c}-0.256 \\
(0.995)\end{array}$ & $\begin{array}{c}-1.44^{*} \\
(0.74)\end{array}$ & $\begin{array}{l}-4.29 \\
(3.96)\end{array}$ & $\begin{array}{l}-1.05 \\
(1.18)\end{array}$ \\
\hline $\mathrm{CAH} \times$ Closest $/ 100$ & $\begin{array}{l}-3.47 \\
(5.97)\end{array}$ & $\begin{array}{c}-16.2^{* * *} \\
(3.81)\end{array}$ & $\begin{array}{c}-12.2^{* * *} \\
(2.82)\end{array}$ & $\begin{array}{l}-6.43 \\
(15.5)\end{array}$ & $\begin{array}{l}-1.92 \\
(4.72)\end{array}$ \\
\hline Ever $\mathrm{CAH} \times$ Dist $/ 100$ & $\begin{array}{c}0.362^{* * *} \\
(0.096)\end{array}$ & $\begin{array}{c}1.40^{* * *} \\
(0.08)\end{array}$ & $\begin{array}{c}1.80 * * * \\
(0.06)\end{array}$ & $\begin{array}{c}1.49^{* * *} \\
(0.31)\end{array}$ & $\begin{array}{c}1.12^{* * *} \\
(0.08)\end{array}$ \\
\hline Ever $\mathrm{CAH} \times$ Closest & $\begin{array}{c}0.743^{* * *} \\
(0.038)\end{array}$ & $\begin{array}{c}0.639^{* * *} \\
(0.029)\end{array}$ & $\begin{array}{c}0.532^{* * *} \\
(0.022)\end{array}$ & $\begin{array}{c}0.641^{* * *} \\
(0.116)\end{array}$ & $\begin{array}{c}0.719^{* * *} \\
(0.032)\end{array}$ \\
\hline $\begin{array}{r}\text { Ever CAH× } \\
\text { Trend/100 }\end{array}$ & $\begin{array}{c}-8.14^{* * *} \\
(0.62)\end{array}$ & $\begin{array}{c}-1.11^{* *} \\
(0.516)\end{array}$ & $\begin{array}{c}0.027 \\
(0.428)\end{array}$ & $\begin{array}{c}2.18 \\
(2.03)\end{array}$ & $\begin{array}{c}-0.664 \\
(0.545)\end{array}$ \\
\hline Patients $\times$ Choices & $2,429,930$ & $3,235,314$ & $4,344,669$ & 191,486 & $2,664,897$ \\
\hline
\end{tabular}


Table 10: MNL Parameter Estimates for Specific MDCs for all Payer Types

\begin{tabular}{|c|c|c|c|c|c|c|c|}
\hline & $\begin{array}{c}\text { Circulatory } \\
\text { system }\end{array}$ & $\begin{array}{l}\text { Digestive } \\
\text { system }\end{array}$ & Injuries & $\begin{array}{l}\text { Mental } \\
\text { diseases }\end{array}$ & $\begin{array}{c}\text { Musculoskeletal } \\
\text { system }\end{array}$ & $\begin{array}{l}\text { Respiratory } \\
\text { system }\end{array}$ & Other \\
\hline Distance/100 & $\begin{array}{c}-9.39^{* * *} \\
(0.04)\end{array}$ & $\begin{array}{c}-11.5^{* * *} \\
(0.04)\end{array}$ & $\begin{array}{c}-9.83^{* * *} \\
(0.11)\end{array}$ & $\begin{array}{c}-6.49^{* * *} \\
(0.07)\end{array}$ & $\begin{array}{c}-8.25^{* * *} \\
(0.04)\end{array}$ & $\begin{array}{c}-13.0^{* * *} \\
(0.04)\end{array}$ & $\begin{array}{c}-9.74^{* * *} \\
(0.05)\end{array}$ \\
\hline Distance $^{2} / 10,000$ & $\begin{array}{c}1.06^{* * * *} \\
(0.05)\end{array}$ & $\begin{array}{c}2.83^{* * * *} \\
(0.05)\end{array}$ & $\begin{array}{c}2.11^{* * *} \\
(0.13)\end{array}$ & $\begin{array}{c}0.920^{* * * *} \\
(0.071)\end{array}$ & $\begin{array}{c}1.42^{* * *} \\
(0.04)\end{array}$ & $\begin{array}{c}4.11^{* * *} \\
(0.05)\end{array}$ & $\begin{array}{c}1.96^{* * *} \\
(0.05)\end{array}$ \\
\hline Closest Hospital & $\begin{array}{c}0.559^{* * * *} \\
(0.009)\end{array}$ & $\begin{array}{c}0.367^{* * *} \\
(0.008)\end{array}$ & $\begin{array}{c}0.523^{* * *} \\
(0.021)\end{array}$ & $\begin{array}{c}0.398 * * * \\
(0.014)\end{array}$ & $\begin{array}{c}0.418^{* * * *} \\
(0.008)\end{array}$ & $\begin{array}{c}0.313^{* * *} \\
(0.007)\end{array}$ & $\begin{array}{c}0.435^{* * *} \\
(0.009)\end{array}$ \\
\hline Bed Size/1000 & $\begin{array}{c}-2.58^{* * *} \\
(0.14)\end{array}$ & $\begin{array}{c}-0.496^{* * *} \\
(0.148)\end{array}$ & $\begin{array}{c}-1.06^{* * *} \\
(0.38)\end{array}$ & $\begin{array}{c}4.23^{* * *} \\
(0.20)\end{array}$ & $\begin{array}{c}-0.248^{*} \\
(0.129)\end{array}$ & $\begin{array}{c}-1.37^{* * * *} \\
(0.15)\end{array}$ & $\begin{array}{c}-1.22^{* * *} \\
(0.16)\end{array}$ \\
\hline Bed Size $\times$ Dist $/ 100,000$ & $\begin{array}{c}4.27^{* * *} \\
(0.08)\end{array}$ & $\begin{array}{c}3.79 * * * \\
(0.09)\end{array}$ & $\begin{array}{c}3.66^{* * *} \\
(0.22)\end{array}$ & $\begin{array}{c}-0.718^{* * *} \\
(0.117)\end{array}$ & $\begin{array}{c}1.98^{* * *} \\
(0.08)\end{array}$ & $\begin{array}{c}3.64^{* * *} \\
(0.09)\end{array}$ & $\begin{array}{c}3.68^{* * *} \\
(0.09)\end{array}$ \\
\hline Bed Size $\times$ DRG Weight/10,000 & $\begin{array}{c}11.5^{* * * *} \\
(0.07)\end{array}$ & $\begin{array}{c}4.96^{* * *} \\
(0.09)\end{array}$ & $\begin{array}{c}4.88^{* * *} \\
(0.25)\end{array}$ & $\begin{array}{c}5.16^{* * *} \\
(0.70)\end{array}$ & $\begin{array}{c}6.27^{* * *} \\
(0.12)\end{array}$ & $\begin{array}{c}7.68^{* * *} \\
(0.09)\end{array}$ & $\begin{array}{c}6.28^{* * *} \\
(0.11)\end{array}$ \\
\hline CAH Status/100 & $\begin{array}{l}6.85^{*} \\
(3.50)\end{array}$ & $\begin{array}{l}-0.818 \\
(2.74)\end{array}$ & $\begin{array}{c}8.64 \\
(8.77)\end{array}$ & $\begin{array}{c}-28.8^{* * *} \\
(6.62)\end{array}$ & $\begin{array}{c}9.93^{* * *} \\
(3.45)\end{array}$ & $\begin{array}{c}1.59 \\
(2.52)\end{array}$ & $\begin{array}{l}6.04^{*} \\
(3.44)\end{array}$ \\
\hline $\mathrm{CAH} \times$ Dist $/ 1000$ & $\begin{array}{c}-3.54^{* * *} \\
(0.71)\end{array}$ & $\begin{array}{l}-0.513 \\
(0.550)\end{array}$ & $\begin{array}{c}-5.14^{* * *} \\
(1.70)\end{array}$ & $\begin{array}{l}-0.90 \\
(1.20)\end{array}$ & $\begin{array}{c}-2.38^{* * *} \\
(0.66)\end{array}$ & $\begin{array}{c}-0.979^{*} \\
(0.503)\end{array}$ & $\begin{array}{c}-5.01^{* * *} \\
(0.68)\end{array}$ \\
\hline $\mathrm{CAH} \times$ Closest $/ 100$ & $\begin{array}{c}-13.7^{* * * *} \\
(2.82)\end{array}$ & $\begin{array}{c}-7.24^{* * *} \\
(2.16)\end{array}$ & $\begin{array}{c}-25.4^{* * *} \\
(7.03)\end{array}$ & $\begin{array}{c}43.2^{* * *} \\
(5.54)\end{array}$ & $\begin{array}{c}-16.5^{* * *} \\
(2.82)\end{array}$ & $\begin{array}{c}-10.1^{* * *} \\
(1.94)\end{array}$ & $\begin{array}{c}-11.1^{* * *} \\
(2.75)\end{array}$ \\
\hline Ever $\mathrm{CAH} \times$ Dist $/ 100$ & $\begin{array}{c}0.889^{* * * *} \\
(0.049)\end{array}$ & $\begin{array}{c}1.45^{* * *} \\
(0.04)\end{array}$ & $\begin{array}{c}1.64^{* * * *} \\
(0.12)\end{array}$ & $\begin{array}{c}1.09^{* * *} \\
(0.07)\end{array}$ & $\begin{array}{c}0.786^{* * *} \\
(0.045)\end{array}$ & $\begin{array}{c}1.47^{* * *} \\
(0.04)\end{array}$ & $\begin{array}{c}1.27^{* * *} \\
(0.05)\end{array}$ \\
\hline Ever $\mathrm{CAH} \times$ Closest & $\begin{array}{c}0.746^{* * *} \\
(0.019)\end{array}$ & $\begin{array}{c}0.609 * * * \\
(0.016)\end{array}$ & $\begin{array}{c}0.812^{* * *} \\
(0.048)\end{array}$ & $\begin{array}{c}0.790^{* * *} \\
(0.035)\end{array}$ & $\begin{array}{c}0.877^{* * *} \\
(0.019)\end{array}$ & $\begin{array}{c}0.581^{* * *} \\
(0.015)\end{array}$ & $\begin{array}{c}0.710^{* * * *} \\
(0.020)\end{array}$ \\
\hline Ever $\mathrm{CAH} \times$ Trend $/ 100$ & $\begin{array}{c}-4.40^{* * * *} \\
(0.33)\end{array}$ & $\begin{array}{c}-1.83^{* * *} \\
(0.28)\end{array}$ & $\begin{array}{l}-2.11 \\
(0.82) \\
\end{array}$ & $\begin{array}{c}6.43^{* * *} \\
(0.56)\end{array}$ & $\begin{array}{c}-1.71^{* * *} \\
(0.31)\end{array}$ & $\begin{array}{c}-1.76^{* * *} \\
(0.27)\end{array}$ & $\begin{array}{c}0.695^{* *} \\
(0.333)\end{array}$ \\
\hline Patients $\times$ Choices & $8,975,117$ & $9,813,739$ & $1,310,445$ & $4,168,676$ & $9,582,748$ & $11,173,801$ & $7,019,073$ \\
\hline
\end{tabular}

${ }^{*} p<0.10,{ }^{* *} p<0.05,{ }^{* * *} p<0.01$

Note: Standard errors are in parentheses. Specifications also include hospital fixed effects and year fixed effects. 